\title{
ACOMPANHAMENTO DE ENFERMAGEM EM SAÚDE PÚBLICA, ASSESSORAMENTO PEDAGÓGICO E AGRÍCOLA NUMA COMUNIDADE DE ASSENTADOS SEM-TERRA NA ZONA RURAL: RELATO DE EXPERIÊNCIA*
}

\author{
Jacó Fernando Schneider** \\ Neusa Collet ${ }^{\star \star *}$

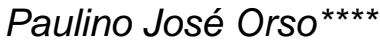 \\ Joaquim Odilon Pereira ${ }^{\star \star \star \star \star}$
}

O estudo relata unia experiência no acompanhamento de Enfermagem, assessoramento pedagógico e agrícola desenvolvido em uma comunidade de assentados sem-terra na zona rural da cidade de Cascavel, estado do Paraná, que teve como premissa básica a integração docente/discente, oferecendo oportunidade de socialização do saber, integração teoria e prática e contato direto com a comunidade. Aponta para a necessidade da enfermagem compreender melhor este tipo de realidade buscando, através da observação e vivência, uma visão critico com possibilidades de intervenção.

UNITERMOS: comunidade rural, enfermagem, educação, agricultura, teoria-prática, integração docente/discente

\footnotetext{
*Projeto de Extensão Universitária desenvolvido pelo Departamento de Enfermagem da Universidade Estadual do Oeste do Paraná - UNIOESTE

**Docente do Departamento de Enfermagem da Universidade do Oeste do Paraná - Campus de Cascavel, mestrando na área Enfermagem Psiquiátrica da Escola de Enfermagem de Ribeirão Preto - USP

${ }^{* *}$ Docente do Departamento de Enfermagem da Universidade do Oeste do Paraná - Campus de Cascavel, mestrando na área Enfermagem Geral e Especializada da Escola de Enfermagem de Ribeirão Preto - USP

****Docente do Departamento de Educação da Universidade do Oeste do Paraná - Campus de Cascavel, mestrando na área de Educação da Universidade Estadual de Campinas - UNICAMP - SP

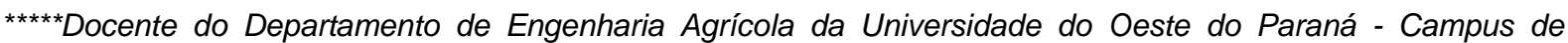
Cascavel, mestre em Engenharia Agrícola
} 


\section{APROXIMAÇÕES A REALIDADE}

Este trabalho pretende dar uma contribuição à questão da interdisciplinariedade e à integração do ensino, pesquisa e extensão razão de ser do ensino superior, da Universidade.

O trabalho foi desenvolvido na região oeste do Paraná. A base da economia da mesma está radicada nas culturas agrícolas. Esta região concentra a mão-de-obra advinda de diversas regiões do país. São Salvador, distrito de Cascavel, local, objeto deste projeto (Comunidade Nova Esperança), compõe-se de um grupo de sem-terra, assentado pelo governo estadual. Este desenvolve atividades voltadas ao cultivo agrícola.

Como seres negados, espoliados, dispõem de parcos recursos financeiros, carecem de saneamento básico, não desfrutam de energia elétrica e, conseguintemente, estão longe de poder usufruir os benefícios que estes poderiam lhes propiciar. Além disso, a água não tratada, e as condições e possibilidades de acesso ao atendimento à saúde e educação são precárias.

No ano de 1989 houve a solicitação, por parte desta comunidade, ao curso de enfermagem da Fecivel ${ }^{\star \star \star \star \star \star}$, para que desenvolvêssemos atividades na área de saúde.

Inicialmente, devido as necessidades imediatas na referida área, desenvolveu-se atendimento de enfermagem com aproximadamente 40 (quarenta) famílias. Este estava direcionado a visita domiciliar com orientações de educação em saúde, saneamento básico, higiene, imunização, puericultura, consulta de enfermagem, planejamento familiar, realização de exame preventivo cérvico-uterino e de mama, incentivo a realização de hortas caseiras.

Com o passar do tempo o número de famílias foi diminuindo, por um processo de seleção interna entre os elementos da comunidade e também por parte do INCRA, restando no ano de 1991 apenas 13 famílias que conquistaram terra e mais 03 (três) famílias que permaneceram no local apesar de não terem recebido terra e dependiam das demais para sobreviver. Portanto o projeto desenvolveu-se com 16 famílias.

Primeiramente, nossa preocupação foi de respeitarmos as pessoas com quem trabalhávamos. Ao mesmo tempo buscamos juntos resgatar a identidade do objeto envolvido - Comunidade Nova Esperança - e a medida do possível romper progressivamente com a realidade, com o sistema dominante, procurando construir uma nova dinâmica, uma nova realidade através de atividades sistematizadas e participativas. Procuramos servir à comunidade como instrumento de reeducação, de mobilização e transformação.

${ }^{\star \star \star \star \star \star}$ Faculdade de Educação, Ciências e Letras de Cascavel - PR 
Sobre a participação, Bordenave ${ }^{2}$ faz a seguinte consideração:

"A participação não é um conteúdo que se possa transmitir, mas uma mentalidade e um comportamento com ela coerente. Também não é uma destreza, que se possa adquirir pelo mero treinamento. A participação é uma vivência coletiva e não individual, de modo que somente se pode aprender na práxis grupal. Parece que só se aprende, a participar, participando".

O que nos motivou a buscar uma abordagem desta natureza foi a apreensão das novas características da realidade. A comunidade estava engajada rio processo de resolutividade de seus problemas, ao mesmo tempo em que apresentava novas necessidades. Neste momento um trabalho assistencialista não respondia aos anseios da comunidade e, tampouco, da equipe técnica. Partiu-se, então, para o desenvolvimento de um trabalho coletivo.

O projeto tinha como objetivos: - a longo prazo: buscar espaços dentro do sistema dominante e articulação com entidades, grupos e associações comprometidas com ideais que visassem a mesma preocupação, isto é, a autonomia, a independência frente aos grupos do poder hegemônico vigente, procurando superar o mesmo; a curto prazo: realizar um trabalho coletivo na busca de alternativas de soluções dos problemas apresentados pela comunidade; possibilitar aos discentes uma aproximação com a realidade e situações que possibilitassem uma intervenção reflexiva e transformadora; oportunizar estudos em grupo visando um maior conhecimento científico, baseados numa fundamentação teórica, como contribuição ao trabalho desenvolvido; promover discussões com grupos da comunidade visando o conhecimento de sua realidade buscando transformações com relação à saúde, educação e agricultura.

As constantes avaliações despertaram para a necessidade de ampliar a equipe, estendendo-se para a área de educação e engenharia agrícola, possibilitando assim uma atuação mais efetiva na tentativa de solucionar os problemas, ajudar a melhorar as condições de vida e transformar a realidade.

O contato com a realidade concreta nos mostrou amplitude, a complexidade e a dimensão dos problemas. Nos demos conta de que, se quiséssemos que nossa intervenção fosse efetiva e eficiente na consecução de nossos objetivos e ria resolução dos problemas era necessário compreendermos profundamente a realidade, termos uma cosmovisão que abrangesse a totalidade e nos engajássemos, nos comprometêssemos, juntamente com a comunidade com a superação daquela situação.

Com esta preocupação foram convidados docentes dos departamentos de Educação e de Engenharia Agrícola da Fecivel objetivando suprir as necessidades percebidas até então pela comunidade, docentes e discentes que atuavam no projeto e que careciam de uma resposta imediata.

Este trabalho, participativo e interdisciplinar, tornou-se possível devido a participação dos três departamentos mencionados. Estes também ofereceram os discentes e docentes que se constituíram na equipe técnica interdisciplinar deste projeto. 


\section{ESTRATÉGIAS PARA ATINGIRMOS OS OBJETIVOS PROPOSTOS}

- Propiciar discussões com os participantes do projeto;

- diagnosticar a realidade atual, com a atuação da comunidade, estudá-la e conhecê-la buscando instrumentalizar, mobilizar e provocar mudança social;

- decidir com docentes, discentes e com a comunidade sobre "o que fazer";

- elaborar material para conhecimento da realidade e trabalhar com questões

culturais da população envolvida;

- propiciar ações educativas em saúde visando a prevenção de doenças e resgatando

junto à comunidade a medicina popular;

- realizar puericultura com orientações sobre imunização, alimentação, vestuário,

acidentes mais comuns na infância e avaliação do crescimento e desenvolvimento

psicomotor da criança;

- prestar atendimento de enfermagem individualizado e/ou em grupo;

- atender a mulher nos diferentes ciclos evolutivos;

- realizar imunização para diminuir o índice de doenças transmissíveis;

- incentivar a agricultura voltada às necessidades da comunidade em primeira

instância e, somente após, para atender ao mercado;

- fornecer material para o professor e auxiliá-lo na prática pedagógica voltada para a açãoreflexão-ação;

- incentivar o cultivo de hortas caseiras e/ou comunitária.

\section{REALIDADE ENCONTRADA}

Apesar de o número de pessoas que participaram do projeto ser relativamente pequeno, a realidade era bastante diversificada.

A população feminina da referida comunidade necessitava de atendimento à saúde, como: exames preventivos de câncer cérvico-uterino e de mamas e, de esclarecimentos sobre planejamento familiar.

A população infantil, formada de escolares e pré-escolar, constituía o maior percentual da comunidade, não tendo acesso ao atendimento de saúde, indispensável para o seu desenvolvimento integral. Tinham acesso à educação primária ( $1^{\mathrm{a}}$ a $4^{\mathrm{a}}$ série) multiseriada na própria comunidade, mas com recursos humanos e materiais precários. As crianças que freqüentavam de $5^{\mathrm{a}}$ a $8^{\mathrm{a}}$ séries, dirigiam-se, a pé, até uma escola municipal no distrito de São Salvador, numa distância de aproximadamente 3 km.

Havia a possibilidade de aproveitamento dos recursos humanos da Instituição 
(UNIOESTE - Fecivel), enquanto formação acadêmica comprometida com a realidade e a necessidade da comunidade, visando a articulação da teoria à prática dos cursos envolvidos no trabalho, numa perspectiva de descentralização do saber e, ao mesmo tempo, emancipação da comunidade na resolução de seus problemas.

Neste sentido, Almeida \& Rocha ${ }^{1}$ colocam que nem sempre os conflitos são gerados ou explicados internamente; é preciso buscar explicações nas relações sociais, nas práticas historicamente determinadas. Portanto, o primeiro ponto a ser considerado é que a investigação tem que contemplar o social numa visão de totalidade do objeto e de suas transformações.

Face ao exposto, nos propusemos à realização deste projeto de atendimento de enfermagem em saúde pública na zona rural, integrado com a pedagogia e com a engenharia agrícola.

\section{DISCUSSÃO SOBRE A PRÁTICA}

Após termos recebido o convite da comunidade para atuação no local, foram realizadas visitas técnicas com o intuito de conhecê-la e verificar as reais condições e possibilidades concretas para a realização do trabalho. A comunidade participou ativamente, juntamente com a equipe, no levantamento da realidade, bem como na formulação de estratégias com vistas ao atendimento das necessidades, dentro da finalidade que inicialmente nos propusemos.

Na participação real os membros influenciam em todos os processos das atividades a serem desenvolvidas. Nem todos os membros participam da mesma maneira, assumindo funções diferentes, porém, a contribuição de todos é indispensável para atingir os objetivos. Bordenave $^{2}$ indica o uso de ferramentas operativas para a participação real concretizar-se, com as quais o grupo realiza sua ação transformadora sobre seu ambiente e sobre seus próprios membros.

As ferramentas operativas das quais o autor fala constituem-se do conhecimento da realidade; a organização que tenha uma intenção transformadora; a comunicação que é fundamental para uma sociedade participativa; a educação para a participação levando o grupo a aprender a conhecer a realidade, a refletir, a superar contradições reais ou aparentes, a identificar premissas subjacentes, a antecipar conseqüências, a atender novos significados das palavras, respeitar opiniões e manejar conflitos; a escolha dos instrumentos através dos quais se realizarão as atividades participativas.

Simplesmente, não podemos chegar aos operários, urbanos ou camponeses, estes, de um modo geral, imersos num contexto colonial, quase umbilicalmente ligados ao mundo da natureza de que se sentem mais partes que transformadores, para, à maneira da 
concepção "bancária", entregar-lhes um modelo de bom homem, entregar-lhes um modelo de bom homem, contido no programa cujo conteúdo nós mesmos organizamos ${ }^{4}$.

As bases filosóficas que nos orientaram não foram àquelas relacionadas ao "modelo clínico ou individual" e de "medicalização" voltados à cura de morbidades e diminuição da mortalidade visando a manutenção da força de trabalho. O enfoque dado foi dirigido às discussões com a comunidade numa perspectiva educativa, preventiva e de desenvolvimento social, buscando bases no "modelo epidemiológico", coletivo, de educação à saúde numa dimensão que instrumentaliza o processo de participação social. Não se trata segundo Valla \& Stotz ${ }^{6}$, de contrapor a luta pelas políticas que modifiquem as condições de saúde da população trabalhadora à luta por um sistema de saúde que garanta a todos uma atenção integral, igualitária, gratuita. Ao movimento popular, através de suas várias organizações, cabe a tarefa de lutar nas duas frentes. As lutas por aumentos salariais reais, pela estabilidade no emprego, pela posse da terra significam ganhos para a saúde e estão indissociavelmente ligadas à conquista de serviço de saúde voltados para a saúde da população.

Semanalmente visitávamos a comunidade, onde eram realizados atendimentos de enfermagem individuais, familiares e grupais, como: consultas de enfermagem, imunização, curativos, orientações individuais, pré-natal e puericultura, palestras em grupo de acordo com a necessidade e solicitação da comunidade, visitas e atendimento a domicílio, atividades de saneamento básico, terapia de re-hidratação oral, encaminhamentos, entre outros. Além disso, eram acompanhados os agricultores e o professor em saia de aula, procurando sempre, não dissociar a família, o trabalho e a educação. Estas atividades foram realizadas no enfoque acima exposto, direcionados à informação, conscientização, capacitação e organização dos indivíduos visando sua emancipação, mas respeitando sua autonomia.

Quando o homem compreende sua realidade, pode levantar hipóteses sobre o desafio dessa realidade e procurar soluções. Assim, pode transformá-la e com seu trabalho pode criar um inundo próprio: seu eu e suas circunstâncias ${ }^{3}$.

Em discussão com a população alvo, chegou-se a conclusão de que era necessário que as pessoas da própria comunidade pudessem resolver os problemas, pois, além da equipe poder estar no local apenas uma vez por semana, não iríamos continuar para sempre na comunidade, pois estaríamos indo contra os nossos propósitos, levar a comunidade à autonomia e gestão própria. Assim, a comunidade, percebendo as limitações e sentindo a necessidade de andar por conta própria, escolheu dois representantes, que, por sua vez, colocaram-se a disposição para atuarem como "agentes de saúde" no período em que a equipe não se fazia presente. Esses dois representantes receberam treinamento da equipe e atuavam resgatando o enfoque de direcionamento dos trabalhos: educação, prevenção e desenvolvimento social, gerindo assim, paulatinamente, sua autonomia.

O acompanhamento na área de saúde estava, de certa forma, atingindo seus objetivos. Mas as necessidades foram aumentando, pois à medida que umas são satisfeitas. criam-se outras. Então ampliou-se para a área da educação e agricultura. Nestas, a instituição tinha mais recursos disponíveis para satisfazer de forma melhor as carências. 
Porém, procuramos não perder de vista o trabalho interdisciplinar quando atuávamos mais diretamente na área de saúde, na escola ou na agricultura, devido a interdependência um do outro.

$\mathrm{Na}$ educação procuramos oferecer suporte crítico, teórico, metodológico e material acompanhando o professor no processo educativo. Na agricultura, criar meios de instrumentalizar os agricultores no manuseio da terra, melhorando a qualidade e aumentando a quantidade de sua produção, sendo que esta era a única fonte de renda das famílias. Incentivamos o cultivo de culturas de subsistência, o aproveitamento de recursos naturais, do adubo orgânico, aproveitamento e cuidado do solo, cultivo de hortas caseiras, apicultura, piscicultura, criação de pequenos animais e aves. Mesmo assim, muitas necessidades ficaram sem ser atendidas, pois dependiam de mais recursos, desde sementes até instrumentos, máquinas agrícolas e escoamento da produção. Estes demandavam verbas e nossa atuação junto à comunidade foi no sentido de mobilizá-la a organizar-se em forma de cooperativas, pois, concretamente, o que a equipe tinha condições de oferecer restringia-se às ações de orientação no tratamento e cultivo da terra, assim como na busca de auxílio financeiro em outras instâncias, acompanhando-os neste processo. Desta forma a comunidade começou a despertar e perceber que era preciso discutir, romper com o imobilismo, com o individualismo, buscar e criar alternativas dentro e fora do seu "habitat". A equipe acompanhava as discussões estimulando-os e orientando-os em suas dúvidas.

Esta forma de trabalho tinha como objetivo que a comunidade se tomasse cada vez mais independente na resolução de seus problemas e que ela mesma criasse alternativas e meios de sobrevivência para melhoria da qualidade de vida.

A comunidade "exigia", devido as suas condições e necessidades, algo que estivesse a seu alcance, popular, portanto. Mas, o que significa participação popular em saúde? Pelo que temos notado em projetos, a intenção é problematizar as questões, estimulando a população a colocar seus pontos de vista e reivindicações sobre a saúde, o sistema que deveria servi-la e a forma pela qual ela se articula com outras áreas e práticas ${ }^{5}$.

Salientamos que nossas dificuldades em atuar na comunidade muitas vezes esbarravam em falta de recursos financeiros e materiais, sendo que a instituição propunhase a fornecer recursos humanos e meio de transporte da equipe. Alguns recursos financeiros para desenvolvimento do trabalho foram conseguidos de instituições financiadoras através de elaboração de projetos específicos de cada área de acordo com as necessidades que a comunidade manifestava. Outro problema enfrentado era o nosso acesso até a comunidade em épocas de chuvas, pois a estrada não era pavimentada e, às vezes, não conseguíamos chegar até o local. Mas os maiores entraves sentidos pela equipe técnica e pela comunidade diziam respeito às políticas externas, às quais tinham que se submeter, numa sociedade capitalista em que só o lucro é visado. A comunidade começou a perceber os obstáculos que haviam em sua caminhada e, por vezes, enfrentava-os 
buscando a melhor maneira de transpô-los. Por outras, desestimulava-se de ir em frente ou esperava que a equipe trouxesse soluções prontas. Isso representa a dificuldade de se construir a auto-gestão, quer por limitações próprias, quer por imposição externa.

Em alguns aspectos, durante os 3 (três) anos de desenvolvimento do projeto, a comunidade tornou-se independente e, por si só, resolvia seus problemas. Como exemplo disso temos as atividades desenvolvidas pelos agentes de saúde que realizavam orientações junto às famílias, encaminhamentos, combate e controle de pediculose e escabiose, acompanhamento das crianças em idade vacinal, curativos simples, orientações quanto ao uso de ervas medicinais e visitas domiciliares. Salientamos que para o desenvolvimento deste trabalho foi imprescindível a atuação dos agentes de saúde.

Por outro lado, a comunidade continuava muito dependente nas questões de agricultura, principalmente relacionadas ao escoamento das safras e falta de recursos financeiros e materiais para o plantio; na área de educação, pelo acompanhamento, foi se observando uma melhora no nível e na qualidade de ensino, percebeu-se um despertar para a reflexão crítica por parte do professor, pais e alunos, refletindo as suas condições e a realidade; quanto à saúde, continuava a dependência em relação aos encaminhamentos a outros níveis, quando necessário, de atendimentos individuais, grupais e domiciliares, ainda que muitos problemas tinham sido solucionados. Outros surgiram com as novas condições criadas, como acompanhamento de doenças crônicas e formas de preveni-las.

Em 1993 o projeto não teve prosseguimento por falta de recursos humanos que se dispusessem a dar continuidade ao mesmo, sendo que alguns docentes que nele atuavam foram liberados pela instituição para cursarem pós-graduação em outros estados. A falta de docentes nos departamentos foi outro agravante da inviabilização do projeto, pois a política

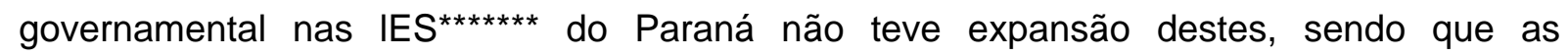
atividades dos docentes que permaneceram na instituição, ficaram restritas a didáticas e continuidade de outros projetos de menor demanda de pessoal e de recursos financeiros.

Antes de encerrarmos nossas atividades na comunidade, como fazíamos sempre, nos reunimos e expusemo-lhes as razões pelas quais estávamos finalizando o projeto. Estimulamos para que continuassem na luta, que reivindicassem de acordo com as necessidades sentidas às instituições ou à órgãos que pudessem auxiliá-los.

As avaliações das práticas foram realizadas, juntamente com a comunidade, no início, durante e ao final do projeto. Estas davam-se basicamente por meio de reuniões e debate no tocante ao trabalho coletivo que vinha sendo desenvolvido. Discutíamos às necessidades apresentadas, com a finalidade de verificar se as mesmas estavam indo ao encontro das perspectivas da comunidade. Nestas reuniões redefiniam-se ações quando necessário e reforçava-se as que estavam respondendo aos seus anseios.

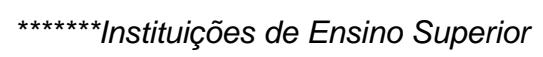




\section{CONSIDERAÇÕES FINAIS}

Quando iniciamos as atividades na comunidade, esta, estava ansiosa para que fôssemos até ela para resolver os seus problemas e transformássemos suas condições de existência, acostumados que estavam com soluções geralmente prontas, paternalistas, vindas de fora. Ao perceberem a forma de condução dos trabalhos, inicialmente, observamos que algumas pessoas não concordaram e outras não acreditaram de que levaria a alguma mudança nas suas condições de vida.

Após alguns meses de exaustivo trabalho, algumas pessoas começaram a perceber a importância do seu efeito engajamento, já que os problemas eram seus e nossos, ao mesmo tempo. Estas pessoas iniciaram um processo de mobilização e

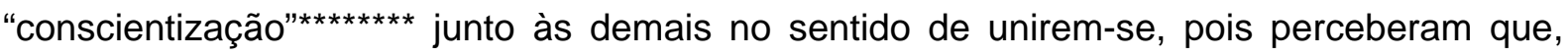
com as condições concretas que vivenciaram, só o trabalho coletivo poderia levar a transformação de sua realidade. Este engajamento não atingiu 100\% (cem por cento) da população, mas a grande maioria se engajou. Estes continuaram o trabalho mobilizados e mobilizando os demais tentando ajudá-los a compreender que, com a estrutura sóciopolítica-econômica vigente, só a coletividade poderia levá-los a conquistar novos espaços, além da terra conquistada na base da luta e mobilização, ainda que pagavam-na com a própria produção.

A conquista da terra foi um fator importante na história e na vida dessas famílias, pois ainda que a conquista desta não bastasse por si só, estas vitórias os animavam na mobilização e na luta por novos objetivos e novos desafios.

Aqui vale mencionar que o projeto não se desenvolveu sempre de forma pacífica e tranqüila. Além dos desafios já mencionados, a equipe também teve que passar por longas discussões, encontros e desencontros. Assim a equipe foi crescendo, adquirindo maior clareza e segurança no trabalho, principalmente dos que o levaram até o fim.

O trabalhador social que atua numa realidade, a qual, mudando, permanece para mudar novamente, precisa saber que, como homem, somente pode entender ou explicar a si mesmo como um ser em relação com esta realidade; que seu "que fazer" nesta realidade se dá com outros homens, equivale dizer, homens em relação, tão condicionados como ele pela realidade e que precisa conhecê-la, atuar criticamente nela para mudar a si, os outros e conseqüentemente a realidade ${ }^{3}$.

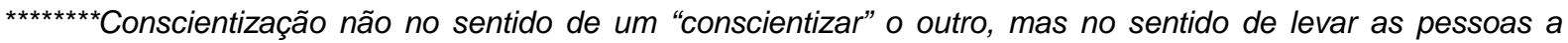
perceberem a importância da participação de todos, pois cada um fazia parte da totalidade da comunidade
} 


\section{Agradecimentos}

Aos docentes que participaram durante o andamento do projeto: Alcy A. L.. Souza, Monica A. da Silva, Wainer M. D. Sampaio, Terezinha de Jesus E. Leão, Maria Lucia F. Rizzoto, Gessi M. Felizari, Marisa I. Tomazzoni, e aos discente do curso de enfermagem, pedagogia e engenharia agrícola; Ao departamento de educação, enfermagem, engenharia agrícola e a coordenadoria de extensão universitária da UNIOESTE - Cascavel - PR.

\section{PUBLIC HEALTH NURSING, PEDAGOGICAL AND AGRICULTURAL AD VICE IN A RURAL COMMUNITY OF SETTLED LANDLESS PEOPLE: AN EXPERIENCE}

This study reports an experience in nursing accompaniment, pedagogical and agricultural advice in a community of settled people without land in the countryside of Cascavel, state of Paraná. The basic premise was student/teacher integration offering the opportunity of know/edge socialization, integration of theory and practice and direct contact with the community. It points out that nursing needs a better understanding of this type of reality seeking, by observation and living, a critical vision with the possibility of intervention.

UNIETERMS: country community, nursing, education, agriculture, theory-practice, student/ teacher integration

\section{ACOMPAÑAMIENTO DE ENFERMERÍA EN SALUD PÚBLICA, ASESORAMIENTO PEDAGÓGICO Y AGRÍCOLA EN UNA COMUNIDAD DE ASENTADOS "SIN TIERRA" EN LA ZONA RUAL: RELATO DE EXPERIENCIA}

El estudio relata una experiencia en el acompañamiento de enfermería, asesoramiento pedagógico y agrícola desarrollado en una comunidad de asentados "sin tierra" en la zona rural perteneciente al municipio de Cascavel, estado del Paraná, que tuvo como principio básico la integración docente/alumno, ofreciendo oportunidad de socialización del saber, integración teoría y práctica y contacto directo con la comunidad. Señala la necesidad de la enfermería comprender mejor este tipo de realidad, buscando por medio de la observación y vivencia, una visión crítica con posibilidades de intervención.

UNITERMOS: comunidad rural, enfermería, educación, agricultura, teoría-práctica, integración docente/alumno 


\section{REFERÊNCIAS BIBLIOGRÁFICAS}

01. ALMEIDA, M. C. P.; ROCHA, J. S. Y. O saber de enfermagem e sua dimensão prática. São Paulo: Cortez, 1986.

02. BORDENAVE, J. E. D. O que é participação. São Paulo: Brasiliense, 1983.

03. FREIRE, P. Educação e mudança. São Paulo: Paz e Terra, 1990.

04. Pedagogia do oprimido. Rio de Janeiro: Paz e Terra, 1970.

05. MINAYO, M. C. S. (org). A saúde em estado de choque. Rio de Janeiro: Espaço e Tempo, 1986.

06. VALLA, V. V.; STOTZ, E. N. (orgs). Participação popular, educação e saúde: teoria e prática. Rio de Janeiro: Relume - Dumará, 1993. 